\title{
Abnormal movements associated with oropharyngeal dysfunction in a child with Chiari I malformation
}

\author{
Stphanie Berthet ${ }^{1}$, Louis Crevier $^{2}$ and Colette Deslandres ${ }^{1,3^{*}}$
}

\begin{abstract}
Background: Chiari I malformations (CM I) are rare hindbrain herniations. Dysphagia and other oropharyngeal dysfunctions may be associated with CM I, but to our knowledge, no clinical presentation similar to ours has ever been reported. The purpose of this communication is to draw attention to a unique and atypical clinical presentation of a child with $\mathrm{CM}$ I.

Case presentation: A 7-year-old boy was evaluated for a two month history of atypical movements which would occur in the evening, and last for an hour after eating. These stereotypical movements with the head and chest bending forward and to the left side, accompanied by a grimace, were associated with sensation of breath locking without cyanosis. Pain and dysphagia were absent. The neurological examination was normal. The possibility of Sandifer syndrome posturing occurring with gastroesopageal reflux disease was considered but neither pain nor back hyperextension were associated with the atypical movements. Neither proton pump inhibitors (PPI) nor prokinetic agents improved his symptoms.

Upper endoscopy and esophageal biopsy did not reveal eosinophilic esophagitis nor reflux esophagitis. Ear, throat and nose (ENT) exam was normal. A severe gastroparesis was demonstrated on milk scan study. Two 24 hour oesophageal $\mathrm{pH}$ probe studies pointed out severe gastroesophageal reflux (GER). High resolution manometric evaluation of the oesophagus revealed normal sphincter pressures and relaxations with no dysmotility of the esophageal body. Electroencephalography and polysomnography were normal. A brain magnetic resonance imaging (MRI) was performed and revealed a CM I: cerebellar tonsils extending to $12 \mathrm{~mm}$, with syringomyelia (D4-D5).

For a long period of time, the child s abnormal movements were considered to be nothing but tics and the CM I a fortuitous finding. Since the child remained symptomatic despite medical treatment, it was decided to proceed with surgery. One year after the onset of his symptoms, he underwent posterior fossa decompression with upper cervical laminectomy and expansion duroplasty. Postoperative MRI confirmed adequate decompression. His atypical posture and dyspnea completely resolved after surgery and he remains asymptomatic two years later.
\end{abstract}

Conclusion: Children may have atypical presentations of CM I. Thus, CM I diagnosis should be considered in unexplained atypical oropharyngeal dysfunctions.

Keywords: Chiari I malformation, Oropharyngeal dysfunction, Abnormal movements, Gastroesophageal reflux (GER), Gastroesophageal reflux disease (GERD)

\footnotetext{
*Correspondence: colette.deslandres@umontreal.ca

'Department of Pediatric Gastroenterology Hepatology and Nutrition, $\mathrm{CHU}$

Sainte Justine, University of Montreal, Montreal, QC, Canada

${ }^{3} \mathrm{CHU}$ Sainte Justine, 3175, Cte Sainte Catherine, H3T1C5 Montral, QC,

Canada

Full list of author information is available at the end of the article
}

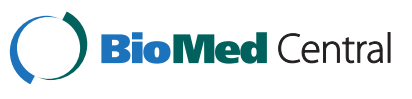

2014 Berthet et al.; licensee BioMed Central. This is an Open Access article distributed under the terms of the Creative Commons Attribution License (http://creativecommons.org/licenses/by/4.0), which permits unrestricted use, distribution, and reproduction in any medium, provided the original work is properly credited. The Creative Commons Public Domain Dedication waiver (http://creativecommons.org/publicdomain/zero/1.0/) applies to the data made available in this article, unless otherwise stated. 


\section{Background}

Chiari I malformations (CM I) are rare hindbrain herniations that may be present in children or adults. CM I is characterized by an abnormal position of the cerebellar tonsils, which herniate outside the cranial cavity into the upper cervical canal: this is associated with an obliteration of the subarachnoid spaces at the level of the foramen magnum [1,2]. Anomalies associated with CM I include syringomyelia. CM I can be easily identified on magnetic resonance imaging (MRI) of the cranio-vertebral junction [3]. Tonsillar herniation of $5 \mathrm{~mm}$ below the foramen magnum is the most common cut off for radiological diagnosis of CM I [4]. More recently, because of the ease of diagnosis and increased clinical awareness, pediatric cases are increasingly reported [5]. Many studies have reported symptoms such as headaches, scoliosis or neurological troubles which were attributed to compression of neural structures. Dysphagia and other oropharyngeal dysfunctions have also been reported but, to our knowledge, no clinical presentation similar to ours has ever been reported.

The purpose of this communication is to draw attention to a unique and atypical clinical presentation of a child with CM I.

\section{Case presentation}

A 7-year-old boy was evaluated for a two month history of atypical movements presenting in the evening, and lasting an hour after eating. These stereotypical movements with the head and chest bending forward and to the left side, accompanied by a grimace were associated with sensation of breath locking without cyanosis. Pain and dysphagia were absent. The neurological examination was normal. The possibility of Sandifer syndrome posturing occurring with gastroesophageal reflux disease (GERD) was considered but neither pain nor back hyperextension were associated with the atypical movements. PPI did not improve his symptoms. Various prokinetic agents (metoclopramide, motilium, cisapride and erythomycin) were also inefficient.

Upper endoscopy and esophageal biopsy did not reveal eosinophilic esophagitis or other abnormalities. ENT exam was normal. A severe gastroparesis was demonstrated on milkscan study. Two 24 hour esophageal $\mathrm{pH}$ probe studies pointed out severe GER. High resolution manometric evaluation of the oesophagus revealed normal sphincter pressures and relaxations with no dysmotility of the esophageal body. Electroencephalography and polysomnography were normal. Because of the unexplained dyspnea associated with this abnormal posture, a head MRI was performed and revealed a CM I: cerebellar tonsils extending to $12 \mathrm{~mm}$, with syringomyelia (D4-D5) (Figure 1).

For a long period of time, the child abnormal movements were only considered to be tics and the CM I was

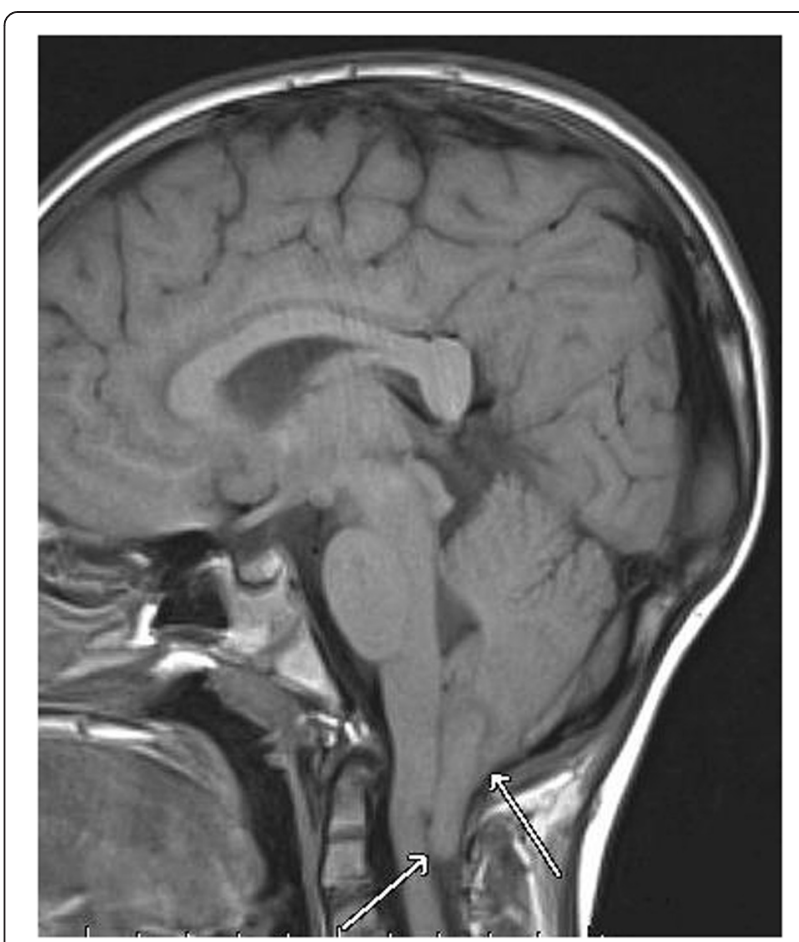

Figure 1 Cerebellar tonsils herniation on magnetic resonance imaging: Chiari malformation type I.

considered a fortuitous finding. Since the child remained symptomatic despite medical treatment, it was eventually decided to proceed with surgery. The operative procedure was done one year after the onset of his symptoms. He underwent posterior fossa decompression with upper cervical laminectomy and expansion duroplasty. No postoperative complication occurred. Postoperative MRI confirmed adequate decompression. His atypical posture and dyspnea completely resolved in the week after surgery. More than two years after surgery, the child remains asymptomatic. The patient and parents have refused any further invasive testing (such as a control esophageal $\mathrm{pH}$ probe study) as the patient was symptom free.

\section{Discussion}

Although CM I is increasingly detected in children $[3,5]$, much remains unknown about its natural history. The pathophysiology of CM I and its associated anomalies have been the subject of considerable debate [1]. Chiari I is a multifactorial condition that is thought to result from a congenital small posterior fossa. Neurologic signs and symptoms may be related directly to a tight foramen magnum associated with the cerebellar tonsillar herniation, with compression and/or distorsion of the medulla and lower cranial nerves.

In adults, the most common clinical symptoms are posterior headaches and/or neck pain exacerbated by Valsava maneuvers [4]. The clinical presentation of young children 
with CM I differs from that of older children and adults. Albert et al. showed that patients aged 0 to 2 years were much more likely to have oropharyngeal dysfunction, whereas those aged 3 to 5 years were more likely to have syringomyelia, frequently associated with scoliosis [6]. CM I pediatric presentations from published series are reported in Table 1. These retrospective series include both operated and non operated CM I patients: 26 to $37 \%$ of the patients $[4,7]$ were asymptomatic with a fortuitous discovery, while the remaining had a variety of neurological symptoms including headaches, ataxia, sensory or motor deficits and lower cranial abnormalities. The most common symptoms were headaches and scoliosis [5].

Oropharyngeal dysfunction is not frequently reported. In fact, in Tubbsstudy on 500 cases of pediatric CM I, oropharyngeal dysfunction only represented $4 \%$ of the symptoms [5]. In some studies involving over 100 patients no esophageal symptoms were reported [1,4,7]. Moreover, these dysfunctions are often poorly described, and can manifest with cough, stridor, dysphagia, abnormal vocal cord movement, GERD, aspiration, prolonged feeding, vomiting, sleep apnea or failure to thrive [3,6]. Perkin et al.
[8] have reported common dysphagia in patients with CM1 malformation by traction of the lower cranial nerves secondary to the herniation by the CM1 malformation. Dysphagia is associated with a global impairment of all phases of swallowing on videofluoroscopy. As they mention dysphagia may be the presenting symptom in some patients.

Cardi et al. [9] described gastroparesis as a cause of Sandifer syndrome. Indeed gastroparesis may enhance GERD and thus subsequently induce a Sandifer syndrome. Our patient had a very unusual presentation and we initially thought that he presented with an atypical case of Sandifer syndrome as he had well documented severe gastroparesis and GERD. We do not exclude that he might have had pre-existing asymptomatic gastroparesis. Deterioration of his CMI might have worsened his gastroparesis. We were unable to obtain invasive diagnostic procedures (as esophageal $\mathrm{pH}$ probe study) after the patients surgery but we did obtain a milk scan study a year after surgery which showed improved but persistent gastroparesis in an absolutely symptom free patient. Neurological and gastrointestinal symptoms are frequently associated in different neurological conditions.

Table 1 Clinical presentations of Chiari malformation type I in children

\begin{tabular}{|c|c|c|c|c|c|c|c|}
\hline & $\begin{array}{l}\text { Tubbs et al. [5] } \\
\text { Alabama }\end{array}$ & $\begin{array}{l}\text { Benglis et al. } \\
\text { [4] Miami }\end{array}$ & $\begin{array}{l}\text { Caldarelli et al. } \\
\text { [2] Roma }\end{array}$ & $\begin{array}{l}\text { Greenlee et al. } \\
\text { [3] lowa }\end{array}$ & $\begin{array}{l}\text { Albert et al. } \\
\text { [6] lowa }\end{array}$ & $\begin{array}{l}\text { Aitken et al. [7] } \\
\text { San Francisco }\end{array}$ & $\begin{array}{l}\text { Park et al. [1] } \\
\text { Boston }\end{array}$ \\
\hline Study period & $1989-2010$ & 1999-2008 & 1993-2005 & $1987-2001$ & $1984-2007$ & 1997-1998 & 1988-1996 \\
\hline No. of children & 500 & 124 & 30 & 31 & 39 & 51 & 68 \\
\hline Inclusion criteria & - & no surgery & symptomatic & age $<6$ & age $<6$ & age $<20$ & - \\
\hline Retrospective study & yes & yes & yes & yes & yes & yes & yes \\
\hline Age at diagnostis & 11 & 7 & 5,5 & 3,5 & 3,5 & 11 & 12 \\
\hline Male $\%$ & 54 & - & 40 & 42 & 39 & - & 48 \\
\hline Surgery & 500 & 0 & 30 & 25 & 39 & 8 & 68 \\
\hline Asymptomatic \% & - & 35 & 0 & - & - & 37 & - \\
\hline Serious manifestations \% & - & - & - & - & - & - & - \\
\hline Loss of consciousness $\%$ & 1,2 & 1,6 & - & - & - & 4 & - \\
\hline Headache \% & 40 & 39 & 57 & 23 & 46 & 55 & 63 \\
\hline Neck pain $\%$ & - & 11 & - & - & - & 12 & - \\
\hline Ataxia \% & 4 & - & 20 & - & - & 8 & 16 \\
\hline Sleep apnea \% & 5 & - & 20 & 29 & - & - & - \\
\hline Motor deficit \% & 10 & 4 & 70 & 3 & - & 20 & 45 \\
\hline Sensory deficit \% & - & 12 & 36 & 6 & - & 6 & - \\
\hline Scoliosis \% & 18 & 4 & 7 & 23 & 28 & 2 & 16 \\
\hline $\begin{array}{l}\text { Dysphagia, oropharyngeal } \\
\text { dysfunction \% }\end{array}$ & 4 & - & 7 & 35 & 74 & - & - \\
\hline Vomiting \% & 3 & 16 & 3 & - & - & - & - \\
\hline Dyspnea \% & 1,2 & - & - & - & - & - & - \\
\hline Dysarthria \% & 5 & - & 7 & - & - & 4 & - \\
\hline Abnormal movement & - & - & - & 19 & - & - & - \\
\hline
\end{tabular}

- = no value. 
Greenlee et al. reported abnormal movements in 6 children with CM I but did not describe them [3]. To our knowledge, no study has reported abnormal movements related to eating in association with CM I.

In conclusion, our patients presentation is clearly unique and the total resolution of symptoms following posterior fossa decompression surgery confirms the link between the abnormal postures and CM I. Again, we were unable to perform control studies following surgery due to the patient and the parents decision to not perform any further invasive testing.

In the literature, complications occur in only $2.4 \%$ of the patients undergoing decompressive surgery for CM I [5]. Spontaneous resolution of childhood CM I has been described in several cases [10]. The Benglis study represents the largest series of pediatric patients with CM I followed without surgery. No new neurological deficits were observed during the follow up period in this population [4], adding to the controversy regarding the indication for surgery [7]. Therefore, pediatric patients with CM I who are not clearly symptomatic and do not have a syrinx or scoliosis, should not undergo surgery [4].

\section{Conclusion}

Symptomatic CM I are being increasingly recognized in young children. The availability of MRI has certainly contributed to this phenomenon. As shown in our case, children may present with atypical manifestations, making CM I a complex clinical diagnostic challenge. CM I should be considered in the differential diagnosis of atypical oropharyngeal dysfunction.

\section{Consent}

Written informed consent was obtained from the patients parents and assent was obtained from the patient (as he was too young for a written consent) for publication of this case report and any accompanying images. A copy of the written consent is available for review by the Editor of this journal. The study was approved by the local institutional board.

\section{Abbreviations}

CM 1: Chiari l; PPI: Proton pump inhibitors; ENT: Ear, throat and nose; MRI: Magnetic resonance imaging; GERD: Gastroesophageal reflux disease; GER: Gastroesophageal reflux.

\section{Competing interests}

The authors declare that they have no competing interests.

\section{Authors contributions}

SB: Conducted a critical analysis of the case reviewed the literature and wrote the manuscript. LC: Revised the manuscript and added a critical review to the surgical part of the manuscript. CD: Conceived of the study, participated in its design and coordinated and helped to draft and edit the final manuscript. All authors read and approved the final manuscript.

\section{Acknowledgements}

We acknowledge the pediatric gastroenterology, hepatology and nutrition service of the CHU Sainte-Justine, Universit de Montral, Montral, and the pediatric neurosurgery department of CHU Sainte-Justine. We also acknowledge Mrs Nicole Thriault for all her secretarial help and Mrs HIne Restieri for her nursing support to the patient and his family.

\section{Author details}

'Department of Pediatric Gastroenterology Hepatology and Nutrition, CHU Sainte Justine, University of Montreal, Montreal, QC, Canada. ${ }^{2}$ Department of Pediatric Neurosurgery, CHU Sainte Justine, University of Montreal, Montreal, QC, Canada. ${ }^{3} \mathrm{CHU}$ Sainte Justine, 3175, Cte Sainte Catherine, H3T1C5 Montral, QC, Canada.

Received: 7 May 2014 Accepted: 11 November 2014 Published online: 10 December 2014

\section{References}

1. Park JK, Gleason PL, Madsen JR, Goumnerova LC, Scott RM: Presentation and management of Chiari I malformation in children. Pediatr Neurosurg 1997, 26(4):190 196.

2. Caldarelli M, Novegno F, Vassimi L, Romani R, Tamburrini G, Di Rocco C: The role of limited posterior fossa craniectomy in the surgical treatment of Chiari malformation type I: experience with a pediatric series. J Neurosurg (3 suppl pediatrics) 2007, 106(3 suppl):187 195.

3. Greenlee J, Donovan KA, Hasan DM, Menezes AH: Chiari I malformation in the very young child: the spectrum of presentations and experience in 31 children under age 6 years. Pediatrics 2002, 110(6):1212 1219.

4. Benglis D Jr, Covington D, Bhatia R, Elhammady MS, Ragheb J, Morrison G, Sandberg DI: Outcomes in pediatric patients with Chiari malformation type I followed up without surgery. J Neurosurg Pediatrics 2011, 7(4):375 379.

5. Tubbs RS, Beckman J, Naftel RP, Chern JJ, Wellons JC 3rd, Rozzelle CJ, Blount JP, Oakes WJ: Institutional experience with 500 cases of surgically treated pediatric Chiari malformation type I. J Neurosurg Pediatrics 2011, 7(3):248 256.

6. Albert GW, Menezes AH, Hansen DR, Greenlee JD, Weinstein SL: Chiari malformation type I in children younger than age 6 years: presentation and surgical outcome. J Neurosurg Pediatrics 2010, 5(6):554 561.

7. Aitken LA, Lindan CE, Sidney S, Gupta N, Barkovich AJ, Sorel M, Wu YW: Chiari type I malformation in a pediatric population. Pediatr Neurol 2009, 40(6):449 454

8. Perkin GD, Murray-Lyon I: Neurology and the gastrointestinal system. J Neurol Neurosurg Psychiatry 1998, 65(3):291 300.

9. Cardi E, Corrado G, Cavaliere M, Capocaccia P, Matrunola M, Rea P, Pacchiarotti C: Delayed gastric emptying in an infant with Sandifer syndrome. Ital J Gastroenterol 1996, 28(9):518 519.

10. Sun PP, Harrop J, Sutton LN, Younkin D: Complete spontaneous resolution of childhood Chiari I malformation and associated syringomyelia. Pediatrics 2001, 107:182 184.

doi:10.1186/s12887-014-0294-3

Cite this article as: Berthet et al:: Abnormal movements associated with oropharyngeal dysfunction in a child with Chiari I malformation. BMC Pediatrics 2014 14:294.

\section{Submit your next manuscript to BioMed Central and take full advantage of:}

$\bowtie$ Convenient online submission

$\otimes$ Thorough peer review

$\nabla$ No space constraints or color $\nabla$ gure charges

$\otimes I m m e d i a t e$ publication on acceptance

$\triangle$ Inclusion in PubMed, CAS, Scopus and Google Scholar

$\otimes$ Research which is freely available for redistribution 